\title{
Internal structure of a gel leading to NBA-ZSM-5 single crystals
}

\author{
Wilson Aguilar-Mamani $^{1,2} \cdot$ Jonas Hedlund ${ }^{1} \cdot$ Johanne Mouzon $^{1} \mathbb{C}$
}

Published online: 7 February 2018

(c) The Author(s) 2018. This article is an open access publication

\begin{abstract}
Porous gel structures are formed during the synthesis of the zeolite ZSM-5 due to the reaction between a source of aluminosilicate, sodium hydroxide, water and a structure directing agent, such as e.g. tetrapropylammonium (TPA) or $n$-butylamine (NBA). In the present work, the formation of the gel in a heterogeneous system leading to the crystallization of NBA-ZSM-5 zeolite from leached metakaolin was studied extensively. The solid and liquid phases obtained after separation were analyzed by inductively coupled plasma sector field mass spectrometry, dynamic light scattering, extreme high resolution-scanning electron microscopy, energy dispersive spectroscopy, high resolution-transmission electron microscopy, X-ray diffraction and nitrogen gas adsorption. The main gel phase formed after hydrothermal treatment exhibited a sponge-like structure resembling those forming in (Na, TPA)-ZSM-5-based systems. For the first time, the walls of the main gel were shown to be inhomogenous and to possess a biphasic internal structure consisting of a mesoporous skeleton of aluminosilicate nanoparticles embedded in a silicate-rich soluble matrix of soft matter. The data presented in this paper is of primary importance to understand the mechanism by which the gel is consumed and contributes to the growth process of the zeolite crystals.
\end{abstract}

Keywords ZSM-5 $\cdot$ Zeolite $\cdot$ Heterogeneous system $\cdot$ Aluminosilicate gel $\cdot$ Microstructure

\section{Introduction}

Zeolite ZSM-5 is an aluminosilicate with MFI framework which, because of the microporous structure, acts as a molecular sieve with properties that can be applied in catalytic processes, gas separation and ion exchange. The synthesis of this zeolite usually requires sources of silicon and aluminum, water, a mineralizing agent and an organic component acting as a structure directing agent or template. These compounds are combined in various compositions and reacted under hydrothermal conditions [1].

Although there are countless alternatives for the synthesis of ZSM-5 zeolite, synthesis pathways can be grouped into

Electronic supplementary material The online version of this article (https://doi.org/10.1007/s10934-018-0568-5) contains supplementary material, which is available to authorized users.

Johanne Mouzon

johmou@1tu.se

1 Chemical Technology, Luleå University of Technology, Luleå, Sweden

2 Department of Chemistry, Faculty of Science and Technology, San Simon University, Cochabamba, Bolivia two basic systems of crystallization. The first category is related to the crystallization from heterogeneous systems with the formation of a gel directly upon mixing the reactants or in the initial stage of crystallization [2-4]. The gel is an amorphous phase with a certain degree of stiffness and therefore sometimes referred to as solid when the liquid phase can easily be extracted from the stiff mass. The second category is characterized by the absence of a macroscopic gel and is referred to as "clear solution" and considered as a homogenous system [1, 5]. In both systems, the study of the stages and species present during the formation of the crystals has aroused great interest. The main purpose of such studies is to identify the precursor species and understand the transformation into zeolite crystals. A proper understanding of the mechanisms of crystal formation opens the possibility to design zeolites with defined properties for specific applications.

In the last 20 years, advanced analysis techniques have allowed to identify and study intermediate species during nucleation and the early stages of crystallization of MFI zeolite from clear solutions. It is noteworthy that the presence of an amorphous phase in the form of colloidal nanoparticles is observed during the synthesis of silicalite- 1 , the aluminum-free version of ZSM-5, suggesting that the presence 
of a gel precursor is also required as an intermediate stage for crystallization from clear solutions [6]. These primary silica particles that act as precursor species for crystallization [7] are amorphous and in the range of 2-6 nm [8-11]. The primary particles evolve to larger particles in the form of aggregates, in which nucleation and subsequent growth take place [12-14].

However, the mechanisms of crystallization in heterogeneous systems are much more complex to study due to the presence of the macroscopic gel in the beginning of the reaction, which prevents scattering and diffraction methods (e.g. SAXS and DLS) from being used to monitor the crystallization process. Therefore, the main challenge in this system is to identify in which phase (gel and/or liquid) the intermediate phases are formed and to understand how they participate to the development of the first zeolite nuclei. Additionally, another important aspect to consider is the fact that the different phases of the system (i.e. liquid, colloidal phase, amorphous intermediate products, crystals) might be altered by post-synthesis treatments and therefore might suffer changes in terms of properties and/or composition which might lead to erroneous conclusions. In fact, the separation of the synthesis intermediate products unavoidably leads to irremediable changes to at least one of the phases in the system.

In general, the studies of heterogeneous systems for ZSM-5 synthesis have shown experimental evidences of the presence of an amorphous aluminosilicate phase (gel) during the induction period. This gel is often referred to as a secondary amorphous phase, since an amorphous starting reagent such as fumed silica is considered as the primary amorphous phase. The majority of the investigations have focused on the role of the gel in systems based on aluminosilicate hydrogels with tetrapropylammonium (TPA) ions as structure directing agent. In all proposed mechanisms, the aluminosilicate gel acts, at least partially, as the source of nutrient for growth of the zeolite crystals $[2,3,15]$.

All studies are also in agreement with the fact that the gel forming as a secondary amorphous phase is engendered by condensation reactions between silicates and aluminates catalyzed by the presence of $\mathrm{OH}^{-}$ions as mineralizing agent [1], which can lead to different gel morphologies. In particular, two similar porous morphologies have been reported recently for the gel aggregates in systems with moderate concentration leading to ZSM-5. An open dendritic gel structure was first reported by Valtchev and colleagues [16] and a closely related structure depicted as consisting of worm-like particles (WLP) was later reported by Subotić and colleagues [17]. Both groups have clearly evidenced that lower silica/alumina ratios favor thicker structures with larger particles [16, 17].

On the one hand, the open dendritic gel structure was shown to present a glassy aspect with the absence of pores in the case of gels leading to ZSM-5, whereas pores have been observed in gels resulting in other zeolites [16]. On the other hand, the formation of WLPs in gels resulting in ZSM-5 was proposed to stem from the aggregation of primary particles of approximately $3 \mathrm{~nm}$ as well as the coalescence and disaggregation of different intermediates, with aluminum-containing precursor species playing a major role in the aggregation process [18]. However, no clear inhomogeneity or internal structure could be directly evidenced within the WLPs or gel aggregates in these two studies.

In most of the studies, tetrapropylammonium compounds has been studied as structure directing agents for synthesis of ZSM-5 zeolite; however a lesser expensive alternative is the $n$-butylamine which produces single crystals with similar properties than crystals prepared by TPA ions [19]. In a previous work, we studied the crystallization of ZSM-5 with inexpensive $n$-butylamine (NBA) in a milky solution prepared from kaolinite or diatomite using $\mathrm{NaOH}$ as mineralizing agent [20]. The kaolinite system resulted in a gel directly after heating thereby forming a heterogeneous system resembling the aforementioned gels for ZSM-5 synthesis forming dendritic structures with WLPs. In the present study, the internal structure of this type of gel was investigated in detail for the first time.

In this paper, the following nomenclature is employed:

Gel semi-rigid jelly-like phase in the wet state. Two different gels were identified in the solid obtained in this work.

Gel mass the unified gel body observed before drying irrespective of visual appearance.

Solid the dried macroscopic solid mass that was recovered either by filtration of the reaction mixture after aging or decanting the liquid after hydrothermal treatment, irrespective of internal structure and nature (e.g. gel, zeolite crystals, remaining mineral particles and clay platelets).

Liquid the liquid phase that was separated from the reaction mixture after aging by filtration or after hydrothermal treatment by decanting.

Sponge-like or spongeous structure three-dimensional structure consisting of a continuous network of solid forming an interconnected network of porosity.

Walls solid part of the spongeous structure by analogy with the edges of the cell walls of opened cellular structures [21].

Equilibrium refers to the solubility quasi-equilbrium established between the gel and liquid, as defined by Zhdanov [22] and Lowe [23].

\section{Experimental section}

\subsection{Materials}

The reagents used were kaolin (Riedel de Haen, pro analysi), sodium hydroxide (Sigma-Aldrich, reagent grade, $\geq 98 \%$, 
anhydrous pellets), $n$-butylamine (NBA, Sigma-Aldrich, 99.5\%) and hydrochloric acid (Merk, pro analysi 37\%). Deionized and then distilled water was used throughout the work.

\subsection{Sample preparation and characterization}

Leached metakaolin (LMK), which was used as the aluminosilicate source, was prepared from kaolin by following the procedure reported in a previous work [20]. Metakaolinite was leached by a $3 \mathrm{M}$ solution of hydrochloric acid in a round-bottom glass flask under reflux conditions in a thermostated oil bath maintained at $115{ }^{\circ} \mathrm{C}$ for $150 \mathrm{~min}$. The synthesis mixture was prepared by first mixing leached metakaolinite, sodium hydroxide, $n$-butylamine and water. This mixture was stirred for $24 \mathrm{~h}$ at room temperature. The molar composition of the final synthesis mixture was: $32 \mathrm{SiO}_{2}: 1 \mathrm{Al}_{2} \mathrm{O}_{3}: 6 \mathrm{Na}_{2} \mathrm{O}: 5 \mathrm{NBA}: 1068 \mathrm{H}_{2} \mathrm{O}$. The mixture was hydrothermally treated in Teflon lined stainless steel autoclaves kept at either 165 or $169{ }^{\circ} \mathrm{C}$ in an oil bath. After different synthesis times, the reaction was quenched by flushing the autoclave with tap water with a temperature of about $8{ }^{\circ} \mathrm{C}$. Finally, the solid formed at the bottom of the autoclave was collected and either dried at room temperature for $48 \mathrm{~h}$ (i.e. unwashed) or washed several times with water directly after synthesis followed by air drying at $60{ }^{\circ} \mathrm{C}$ overnight. In addition, in order to analyze the remnant solid part after the aging step, the solid was recovered by filtration on filter paper (Munktell, grade $00 \mathrm{H}$, typical retention 1-2 $\mu \mathrm{m}$ ). The filter cake was washed three times with distilled water and dried at $60{ }^{\circ} \mathrm{C}$.

The overall composition of the solid phases was measured by inductively coupled plasma sector field mass spectrometry (ICP-SFMS), where samples of $0.1 \mathrm{~g}$ were fused with $0.4 \mathrm{~g}$ of $\mathrm{LiBO}_{2}$ and dissolved in $\mathrm{HNO}_{3}$ before measurement. The supernatant liquid after synthesis was separated from the solid by careful decantation. The liquid was further passed through a syringe filter with a pore size of $0.2 \mu \mathrm{m}$. The composition of the liquid was analyzed by ICP-SFMS after dilution of the samples with water by a factor of 100 .

Furthermore, the particle size distribution in the liquid phase was measured by dynamic light scattering (DLS). The $\mathrm{pH}$ values of the liquid were measured with a $\mathrm{pH}$-meter (Metrohm, $827 \mathrm{pH} \mathrm{Lab)} \mathrm{prior} \mathrm{to} \mathrm{each} \mathrm{measurement;} \mathrm{the}$ electrode was calibrated using two standard buffer solutions (pH 7.0 and 10.0).

The morphology of the solid samples was investigated with extreme high resolution-scanning electron microscopy (XHR-SEM) using a beam of electrons at +3 or $+1 \mathrm{kV}$ with a bias voltage of $-4 \mathrm{kV}$ using a Magellan 400 (FEI Company, Eindhoven, the Netherlands) instrument. The samples were not coated with any conductive coating prior to inspection. In addition, local and overall compositions were determined by energy dispersive spectroscopy (EDS) on a Merlin SEM (Carl Zeiss, Oberkochen, Germany) instrument using an X-Max $50 \mathrm{~mm}^{2} \mathrm{X}$-ray detector (Oxford Instruments, Abingdon, UK). EDS analysis was performed at acceleration voltages of $3.5,7.5$ and $20 \mathrm{kV}$ using a microinjector to introduce nitrogen gas close to the surface of samples in order to mitigate charging.

High resolution-transmission electron microscopy (HRTEM) characterization was performed by using a JEOL JEM-2100F TEM (Jeol Ltd. Tokyo, Japan) instrument at an operating voltage of $200 \mathrm{kV}$. The samples were prepared by crushing the solid in a mortar and by dispersion in propanol for $2 \mathrm{~min}$ by ultrasonication. Finally, one drop of the suspension was placed and dried on a holey carbon film supported by a TEM copper grid.

The crystallinity of the washed samples was analyzed by X-ray diffraction (XRD) using a PANalytical Empyrean X-ray Diffractometer equipped with Cu LFF HR X-ray tube, a graphite monochromator, and a PIXcel3D detector. The $\mathrm{X}$-ray tube was operated at $40 \mathrm{~mA}$ and $45 \mathrm{kV}$. A $2 \theta$ range from $5^{\circ}$ to $50^{\circ}$ was investigated with a step size of $0.026^{\circ}$. The degree of crystallinity was determinated by following the equation derived by van Hooff [24] and considering the area of characteristic peaks of ZSM- 5 between $22^{\circ}$ and $25^{\circ}$ after background removal.

Nitrogen gas adsorption at $77 \mathrm{~K}$ on the solid phase was measured with a Micromeritics ASAP 2010 analyzer after degassing the samples at $300{ }^{\circ} \mathrm{C}$ for $12 \mathrm{~h}$. The surface area was estimated using the BET equation. The equivalent spherical particle diameter $d$ in nanometer was calculated from the surface area using the equation $d=6000 /(\mathrm{BET}$ surface area in $\left.\mathrm{m}^{2} / \mathrm{g}\right) \times\left(\right.$ density in $\left.\mathrm{g} / \mathrm{cm}^{3}\right)$. The density of $\mathrm{Na}_{2} \mathrm{SiO}_{3}$ (i.e. $2.4 \mathrm{~g} / \mathrm{cm}^{3}$ ) was assumed.

\section{Results}

\subsection{Aging}

After aging of the reaction mixture at room temperature for $24 \mathrm{~h}$, the liquid was rich in silica with a molar Si/Al ratio as high as 588 (Table 1). This was related to the dissolution of the leached metakaolin under the prevailing alkaline conditions. Accordingly, approximately $84 \%$ of the silicon present in the leached metakaolin was transferred to the liquid phase. The liquid was also very rich in sodium, as it contained $98 \%$ of the total amount of sodium. In contrast, only $2 \%$ of the introduced aluminum was found in the liquid phase. On the contrary, the majority of the aluminum was present in the solid phase, which exhibited a molar $\mathrm{Si} / \mathrm{Al}$ ratio of 2.5. As shown in Fig. 1a, the remnant solid was found by XRD to consist of impurities present in natural kaolin, such as quartz, muscovite and orthoclase. Accordingly, the 
Table 1 Molar $\mathrm{Si} / \mathrm{Al}$ and $\mathrm{Na} / \mathrm{Al}$ ratios of the solid components and liquid

\begin{tabular}{lllll}
$\begin{array}{l}\text { Leached } \\
\text { metakao- } \\
\text { lin }\end{array}$ & Impurities & Liquid & $\begin{array}{l}\text { Gel 1 } \\
\text { unwashed }\end{array}$ & Gel 1 washed \\
$16^{\mathrm{a}}$ & $2.5^{\mathrm{a}}$ & $588^{\mathrm{a}}$ & $20^{\mathrm{b}}$ & $13^{\mathrm{b}}$ \\
$0.12^{\mathrm{a}}$ & $0.13^{\mathrm{a}}$ & $247^{\mathrm{a}}$ & $6.5^{\mathrm{c}}$ & $1.2^{\mathrm{c}}$ \\
\hline
\end{tabular}

a Determined by ICP-SFMS

${ }^{\mathrm{b}}$ Determined by EDS (Table S2)

${ }^{c}$ Determined by the method described in the Supplementary Information (Table S4)

solid material after aging was comprised of agglomerated particles, mostly consisting of muscovite clay platelets as revealed in Fig. 1b. The presence of muscovite and orthoclase was responsible for the low $\mathrm{Si} / \mathrm{Al}$ ratio of 2.5 of the solid recovered after aging reported in Table 1 and referred to as impurities.

\subsection{Crystallization stages with respect to gel evolution}

Upon heating of the aged reaction mixture, a gel mass formed within the first $2 \mathrm{~h}$. Typical photographs of the gel mass obtained after $2 \mathrm{~h}$ of synthesis are shown in Fig. S1 before and after drying. Figure 2 shows a sketch of the gel mass that exhibited constant shape and size between 2 and $4 \mathrm{~h}$ of synthesis. It consisted of a main white opaque part (Gel 1) that was covered by a thin translucent layer on the top (Gel 2). Crystallization of the NBA-ZSM-5 single crystals was observed to occur in Gel 1 only.

Based on macroscopic observations of the evolution of the gel mass during the course of synthesis, the curve of the

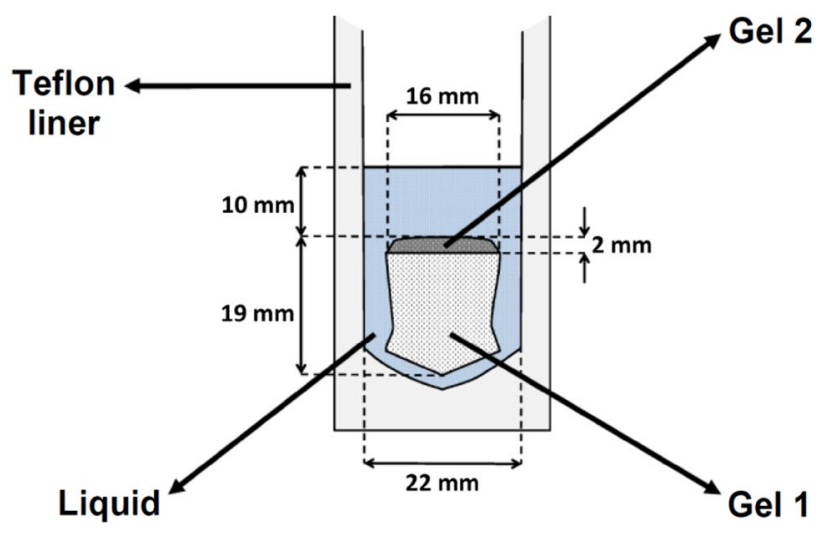

Fig. 2 Sketch of the gel mass observed between 2 and $4 \mathrm{~h}$

XRD crystallinity of ZSM-5 shown in Fig. 3a can be divided into four stages: (I) apparent induction period (from 0 to $2 \mathrm{~h}$ ) corresponding to the formation of the gel mass, (II) crystallization with intact gel mass (from 2 to $4 \mathrm{~h}$ ), (III) crystallization after collapse of the gel mass (from 5 to $6 \mathrm{~h}$ ) and (IV) complete disappearance of the gel and ripening (after $6 \mathrm{~h}$ ).

\subsection{Formation and role of the gel}

The formation of the gel mass during Stage I coincided with decreasing concentrations of silicon and sodium in solution, as shown in Fig. 3b, c, respectively. This shows that silicon and sodium precipates from solution, which results in gel formation. Figure $3 \mathrm{~d}$ shows that the measured concentration of aluminum in the liquid phase during the entire synthesis was low and remained fairly constant from after aging until completion of the synthesis, representing only between 1 and $2 \%$ of the total aluminium present in the system.Therefore,
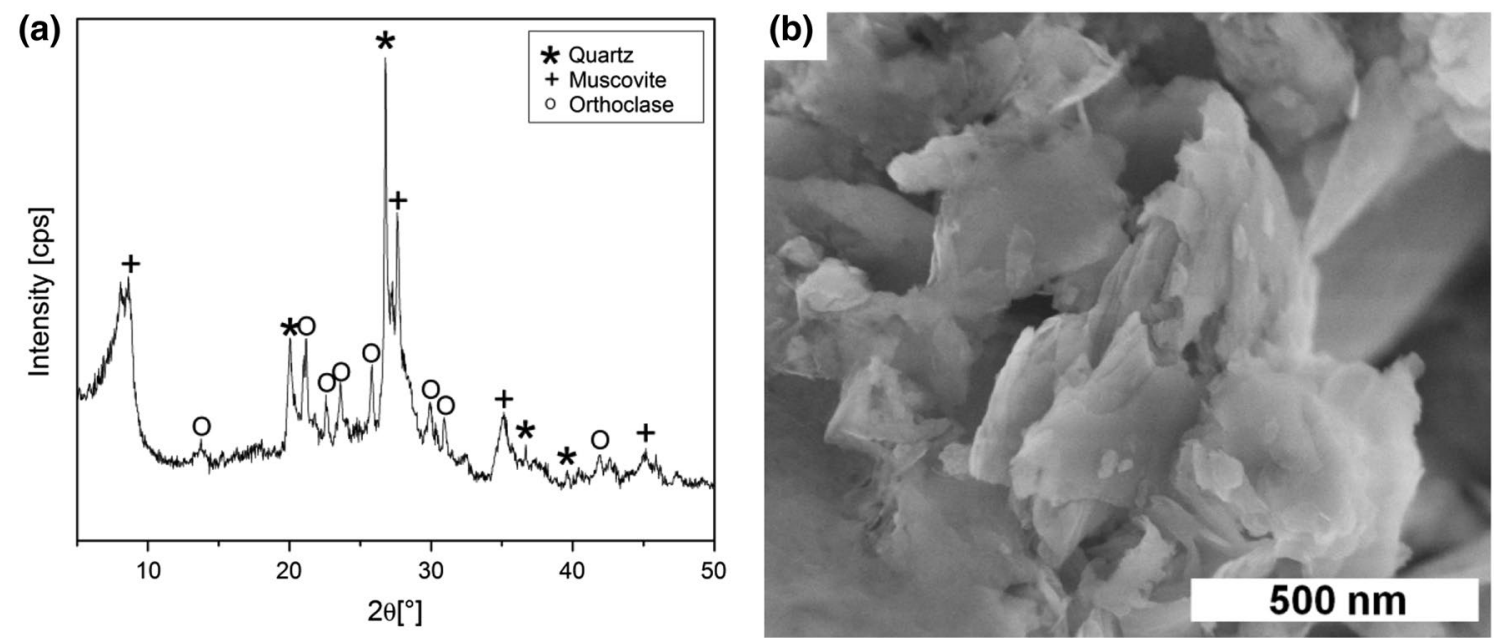

Fig. 1 XRD diffractogram (a) and SEM image (b) of the solid part of the reaction mixture after aging 


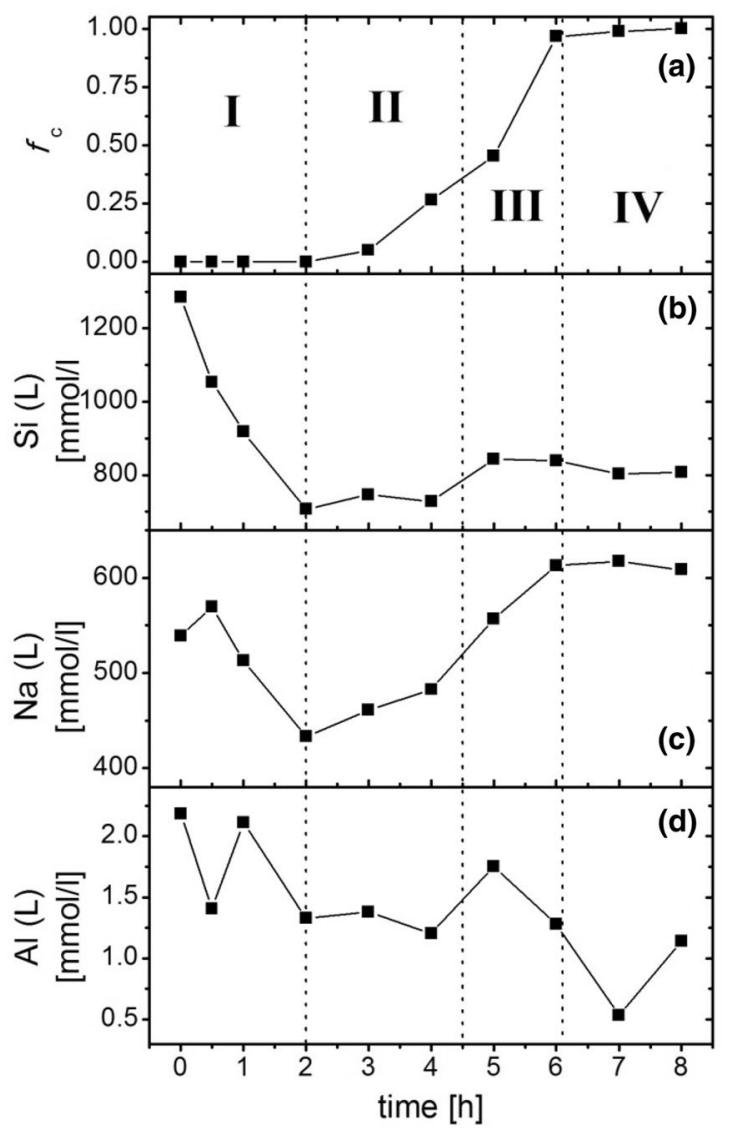

Fig. 3 Evolution as a function of synthesis time of: a ZSM-5 crystallinity, b silicon, c sodium, $\mathbf{d}$ aluminum concentrations in the liquid phase, e diameter of the particles present in liquid phase, $\mathbf{f} \mathrm{pH}, \mathbf{g}$ min-

aluminium present in the solution after aging did not participate to the gel formation. Instead, monomeric aluminate anions $\left(\mathrm{Al}(\mathrm{OH})_{4}^{-}\right)$provided by rapid dissolution of parts of the remaining clays and minerals upon heating during the first hour reacted immediately with larger silicate oligomers as suggested in literature [25]. This is illustrated by the decrease in average diameter measured by DLS between 0 and $1 \mathrm{~h}$ (Fig. 3e) and corroborated by the sharp increase in $\mathrm{pH}$ of the liquid between 0 and $0.5 \mathrm{~h}$ (Fig. 3f) caused by the release of $\left[\mathrm{OH}^{-}\right]$ions to the solution during condensation of the silica oligomers according to the following reaction:

$\equiv \mathrm{SiO}^{-}+\mathrm{HO}-\mathrm{Si} \equiv \leftrightarrow \equiv \mathrm{Si}-\mathrm{O}-\mathrm{Si} \equiv+\mathrm{OH}^{-}$

Subsequently, more sodium and silicon in the form of shorter silicate oligomers were precipitated from the solution and integrated to the gel mass during the second hour, as shown by the decrease of the concentrations in $\mathrm{Si}$ and $\mathrm{Na}$ between 1 and $2 \mathrm{~h}$ in Fig. 3b, c, respectively.

During crystallization (stage II and III), sodium was continuously released from the gel to the liquid phase and the concentration of $\mathrm{Na}$ in the liquid phase (Fig. 3c)

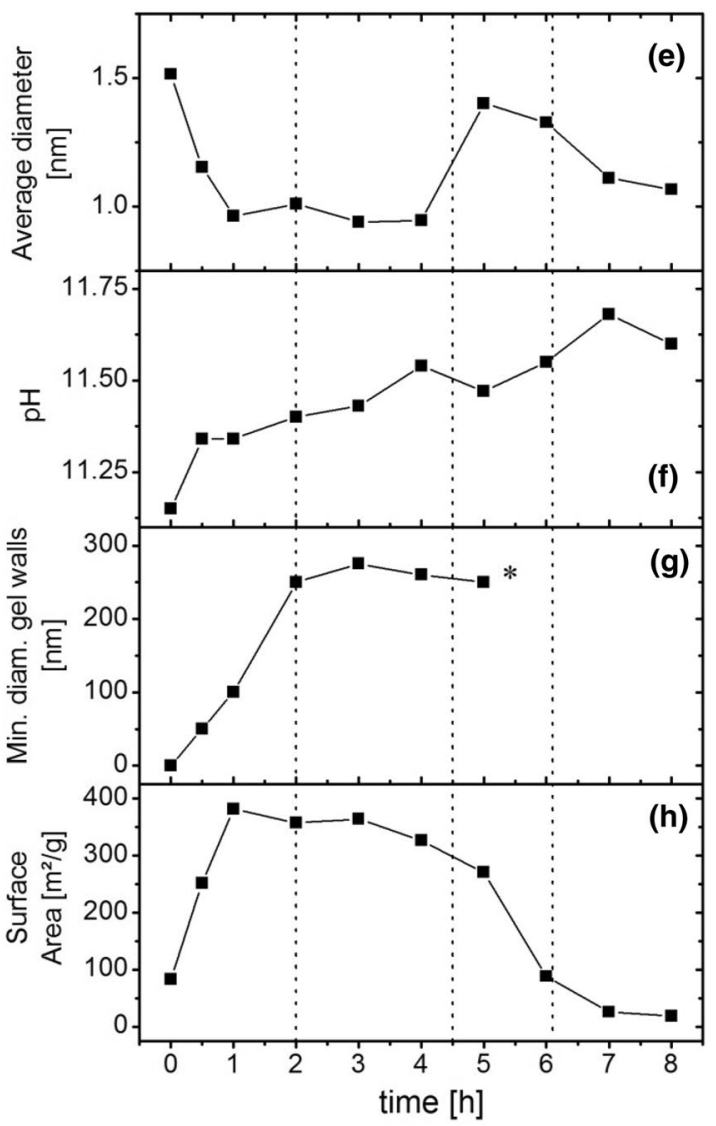

imum diameter of the gel walls (asterisk measurements performed on small fragments of the gel), $\mathbf{h}$ BET surface area of the washed solid phase

followed relatively well the evolution of the XRD crystallinity curve over time (Fig. 3a). In contrast, the concentration of silicon in the liquid phase was relatively constant during the crystallization process (Fig. 3b). The slight increase at the beginning of stage III is believed to be due to the dissolution of the translucent gel part (Gel 2 in Fig. 2) after collapse of the main part of the gel mass (Gel 1 in Fig. 2). This is corroborated by the detection of larger oligomers by DLS during stage III and IV (Fig. 3e) and the decrease of $\mathrm{pH}$ at the transition stage II/III, whereas a steady increase of $\mathrm{pH}$ is characteristic of zeolite crystallization, as previously demonstrated by Lowe [26] or Navrotsky [27].

All these data show that a solubility quasi-equilibrium between the gel mass and solution is reached at the end of stage I and that the quantities of silicon and aluminium stored in the main part of the gel mass (Gel 1 in Fig. 2) equal those incorporated inside the ZSM-5 crystals during stage II and III, independently of the exact transport and identities of the species involved in the growth mechanism. 


\subsection{Gel structure at equilibrium}

The main part of the gel mass after $2 \mathrm{~h}$ (Gel 1 in Fig. 2) was found to consist of a sponge-like structure with cell walls with a minimum diameter in the range of $250 \mathrm{~nm}$, as shown in Fig. 4. It is noteworthy that beyond $2 \mathrm{~h}$, no further growth of the cell walls was observed at longer synthesis times, as shown in Fig. 3g. This confirms that the gel mass reached equilibrium at $2 \mathrm{~h}$. The morphology of the gel walls resembled the open dendritic gel structure and the worm-like particles (WLP) reported by Valtchev [16] and Subotić [17], respectively.

The large open porosity of the opaque part of the gel with sponge-like structure permitted a majority of the liquid phase to be driven off to the outer surface during drying without washing. This was evidenced by the special aspect of the crust forming on the outside of the solid mass and the inward gradient of precipitated species after drying (Figs. S2.1-2.5). The center of Gel 1 was free of appreciable amounts of recrystallized and precipitated species around the gel walls, as shown in Fig. 5a (as well as Figs. S2.5-2.11). Therefore, XHR-SEM imaging and EDS measurements were performed on material issued from this particular region in order to obtain reliable results without contribution from the liquid phase. In Fig. 5b, the XHR-SEM image of a fracture surface of a gel wall shows that the walls appear quite compact with only a minor observable porosity throughout the cross-section and exhibited a granular character.

The presence of clay and minerals impurities as well as the diffusion of $\mathrm{Na}$ and $\mathrm{Si}$ under irradiation of the electron beam caused difficulties to acquire reliable EDS data for the gel walls. However, proper methodologies were developed

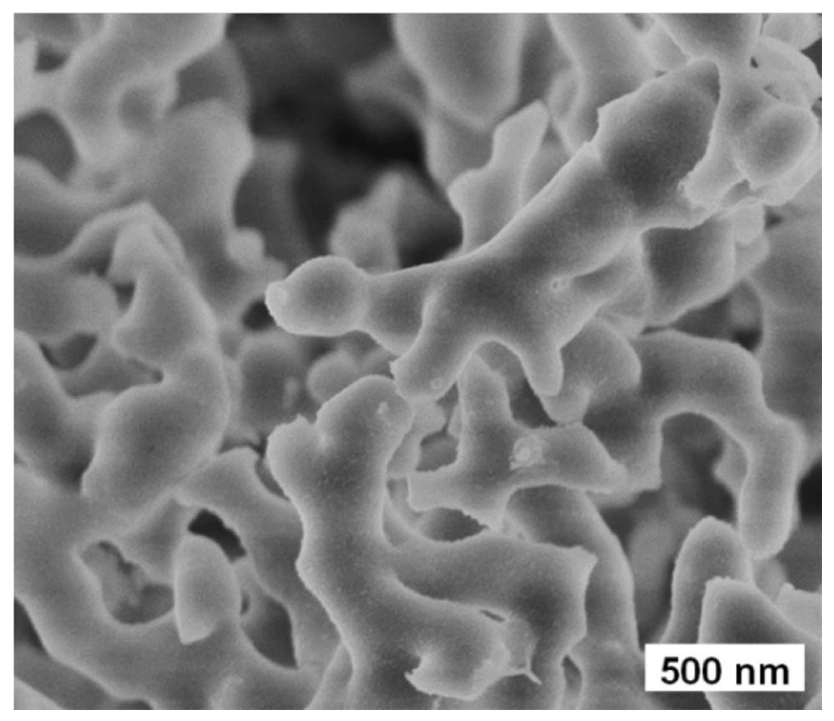

Fig. 4 Scanning electron micrographs showing the spongeous structure found inside Gel 1 and are presented in the Supplementary Information. Accordingly, the gel walls were found to exhibit $\mathrm{Si} / \mathrm{Al}$ and $\mathrm{Na} / \mathrm{Al}$ molar ratios of 20 and 6.5 , respectively (see Table 1).

\subsection{Effect of washing}

If washing was applied directly after completion of synthesis, this caused the gel mass to collapse and the final solid after drying consisted of fragments of the sponge-like structure. The washed fragments after $2 \mathrm{~h}$ were observed to be porous by electron microscopy. Figure $5 \mathrm{c}$ shows a XHRSEM image of the fracture surface of a washed gel fragment. The gel walls were clearly porous and the granular character was striking. These observations were confirmed by HRTEM, as shown in Fig. 6. In Fig. 6a, b, the HR-TEM image of a cross-section of a washed gel fragment after $2 \mathrm{~h}$ reveals the granular character of the internal structure of the gel formed by nanosized grains $<10 \mathrm{~nm}$, as demonstrated by the modulated contrast in Fig. 6b. On the contrary, no particular internal structure could be observed inside the gel without washing, as shown in Fig. 6c, d.

In addition, the $\mathrm{Si} / \mathrm{Al}$ and $\mathrm{Na} / \mathrm{Al}$ ratio in the gel walls were found to decrease to 13 and 1.2 after washing (see Table 1). Therefore, a continuous silicate-rich phase must have been present inside the unwashed gel walls after drying in order to mask the internal porosity revealed after washing. A constant $\mathrm{Si} / \mathrm{Al}$ ratio close to 13 was in fact obtained in the gel walls recovered after all investigated synthesis times, i.e. $13.2,13.4,13.8$ and 12.1 for $2,3,4$ and $5 \mathrm{~h}$, respectively. As the gel walls retained their size after washing as well as in the remaining gel fragments after the collapse of the gel mass, it can be concluded that the gel walls consist of a skeleton of granular particles, with low solubility in water.

The solid skeleton retained after washing was comprised of a network of nanoparticles forming a spongeous structure, as revealed by the high magnification XHR-SEM and HR-TEM images in Figs. 5d and 6b, respectively. This mesoporous skeleton was responsible for the high BET specific surface area of $357 \mathrm{~m}^{2} / \mathrm{g}$ measured for $2 \mathrm{~h}$ of synthesis after washing (Fig. 3h), which corresponds to a comparable equivalent particle diameter of $7 \mathrm{~nm}$ in agreement with Figs. $5 \mathrm{~d}$ and $6 \mathrm{~b}$.

\section{Discussion}

The internal mesoporous skeleton of nanoparticles evidenced after washing is rich in aluminium with a $\mathrm{Si} / \mathrm{Al}$ molar ratio of 13 in comparison to the unwashed gel whose ratio was 20 . Hence, it probably started to form during the complexation of the aluminate ions released by the impurities and the large silicate oligomers present in solution in the beginning of synthesis. The high BET specific surface 


\section{(a)}

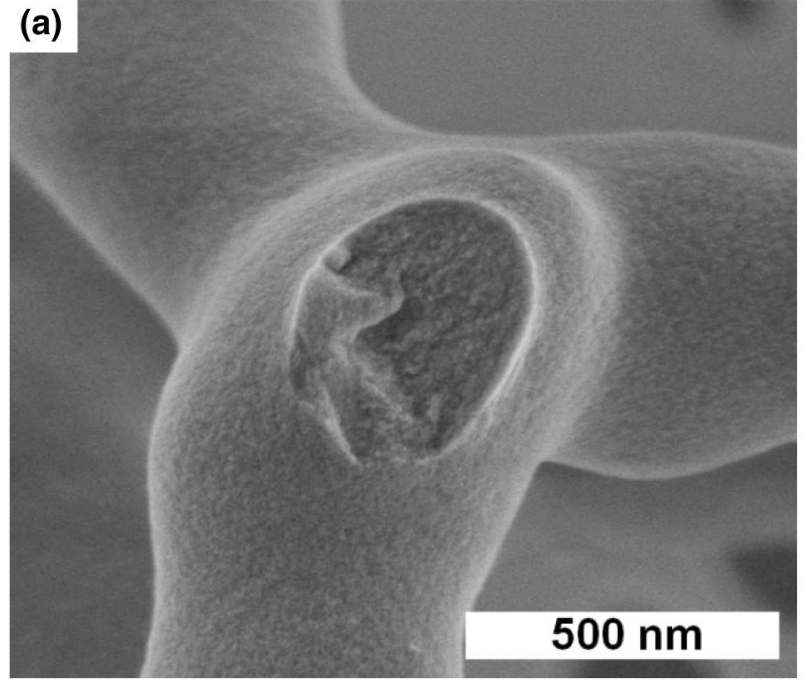

(c)

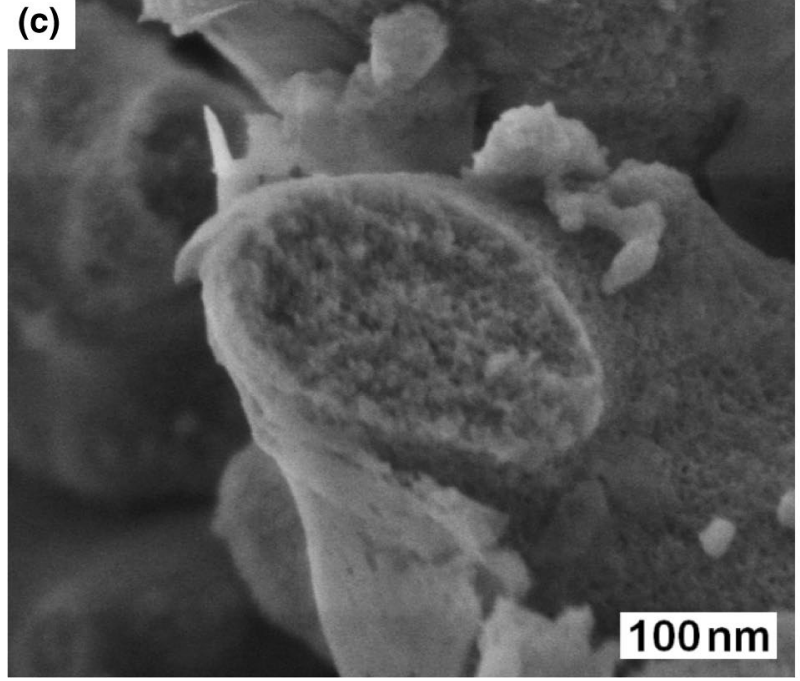

(b)

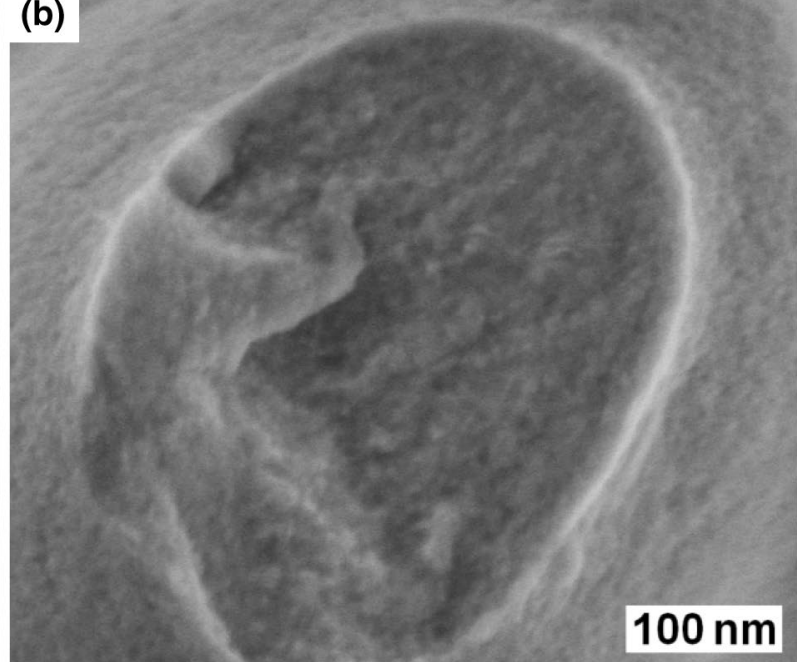

(d)

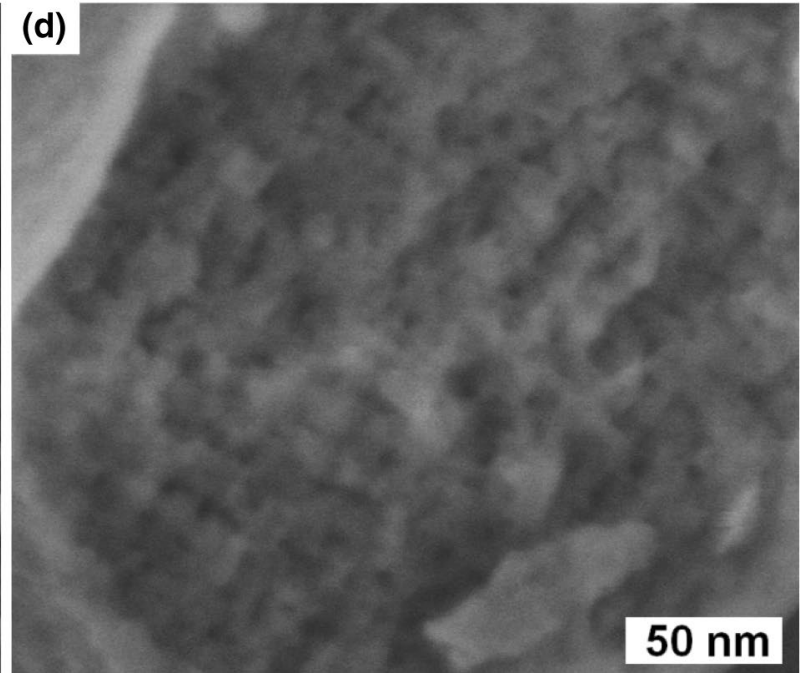

Fig. 5 XHR-SEM images showing fracture surfaces of: a, b the unwashed gel walls at low (a) and high (b) magnification; c, d the washed gel walls at low (c) and high (d) magnification

area measured after $1 \mathrm{~h}$ is comparable to that found for $2 \mathrm{~h}$ (Fig. 3h) and therefore suggests that the nanoparticles were already formed at this early stage, even though the gel walls increased dramatically in size the following hour to reach equilibrium (Fig. 3g).

The continuous water-soluble silicate-rich phase hiding the internal porosity of the gel walls after drying most probably comprise a matrix of soft matter formed by shorter oligomers between 1 and $2 \mathrm{~h}$. As a matter of fact, material left by the liquid inside the gel walls during drying can be ruled out, since there were no direct traces of the dried liquid around the gel walls in the investigated region of the dried solid mass by XHR-SEM (Figs. S2.1-S2.11). Moreover, it is improbable that the liquid was sufficiently concentrated in silicate to completely fill with dry solid the internal porosity of the gel walls that it should have occupied before drying and to cause an increase of the $\mathrm{Si} / \mathrm{Al}$ ratio from 13 to 20 .
Consequently, we propose that the gel at equilibrium has a biphasic structure and consists of a mesoporous skeleton of nanoparticles forming a spongeous network inside a silicate-rich matrix of soft matter, as depicted in Fig. 7.

Recently, a core-shell structure for the final gel aggregates in a system leading zeolite $\mathrm{A}$ has been proposed on the principle that aluminate ions react first and rapidly with the silicate oligomers [28]. In this model, an aluminum-rich core is expected in the center of the gel walls. Our results demonstrate for the first time that this type of compositional inhomogeneity exists also in gels leading to the formation of ZSM-5. However, the expected gradient $\mathrm{Si} / \mathrm{Al}$ in the gel structure is not at the scale of the gel walls, but at a scale below $10 \mathrm{~nm}$. It stems from a mesoporous skeleton of nanoparticles embedded in a silicate-rich matrix of soft matter. 

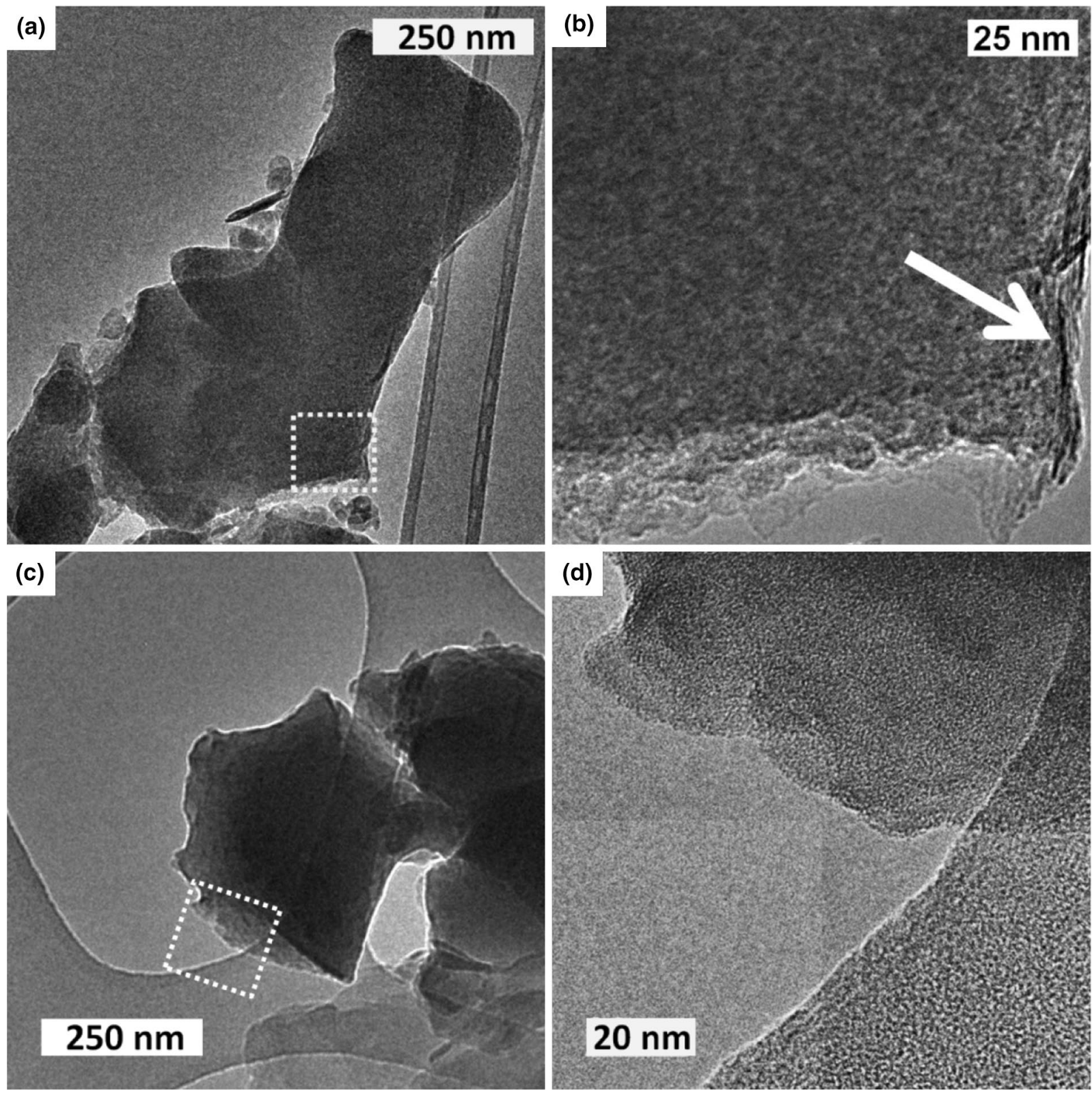

Fig. 6 Cross-section of the gel obtained after $2 \mathrm{~h}$ : a after direct washing $(3 \times)$, $\mathbf{b}$ area corresponding to the delineated area in $\mathbf{a}, \mathbf{c}$ without washing, $\mathbf{d}$ area corresponding to the delineated area in $\mathbf{c}$. The arrow

indicates the presence of small clay platelets on the surface of the gel after drying
Fig. 7 Sketch of a cross-section of the gel walls showing the biphasic internal structure

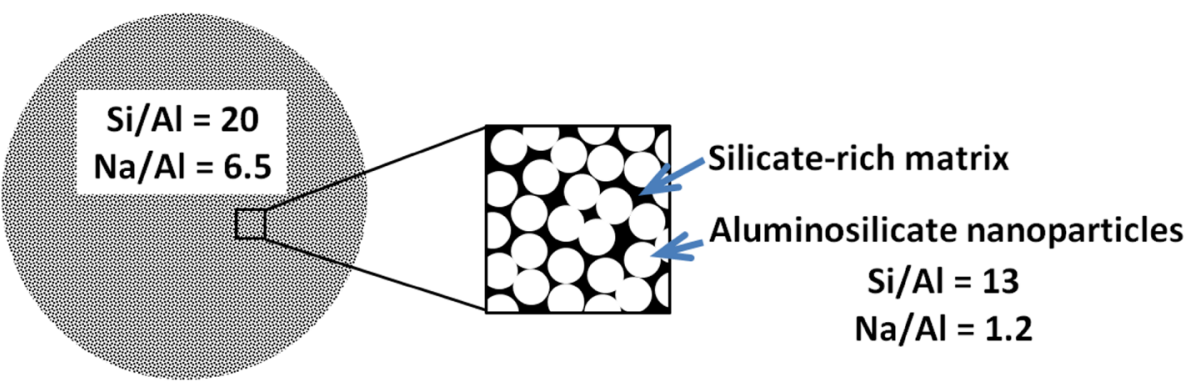




\section{Conclusions}

The formation of the gel in a heterogeneous system leading to the crystallization of (Na, NBA)-ZSM-5 from leached metakaolin was studied. The leached metakaolin produced a solution rich in silica oligomers after aging with the other reagents and aluminium was provided by the dissolution upon heating of the mineral or clay impurities contained in the metakaolin. The main gel phase formed after hydrothermal treatment exhibited a sponge-like structure resembling those forming in (Na, TPA)-ZSM-5-based systems. For the first time, the walls of the main gel were shown by several techniques to be inhomogenous and to possess a biphasic internal structure consisting of a mesoporous skeleton of aluminosilicate nanoparticles embedded in a silicate-rich soluble matrix of soft matter. However, the mechanism by which the aluminosilicate nanoparticles are consumed and how the growth process of the zeolite crystals takes place has to be further investigated.

Acknowledgements The authors gratefully acknowledge financial support from the Swedish International Development Cooperation Agency (SIDA) and Swedish Foundation for Strategic Research. The Knut and Alice Wallenberg foundation is acknowledged for financially supporting the Magellan SEM instrument.

Open Access This article is distributed under the terms of the Creative Commons Attribution 4.0 International License (http://creativeco mmons.org/licenses/by/4.0/), which permits unrestricted use, distribution, and reproduction in any medium, provided you give appropriate credit to the original author(s) and the source, provide a link to the Creative Commons license, and indicate if changes were made.

\section{References}

1. C.S. Cundy, P.A. Cox, Microporous Mesoporous Mater. 82, 1 (2005)

2. E.G. Derouane, S. Determmerie, Z. Gabelica, N. Blom, Appl. Catal. 1, 201 (1981)

3. Z. Gabelica, E.G. Derouane, N. Blom, ACS Symp. Ser. 248, 219 (1984)
4. J.A. Martens, P.A. Jacobs, Stud. Surf. Sci. Catal. 33, 47 (1987)

5. B. Subotić, J. Bronić, T.A. Jelić, in Ordered Porous Solids: Recent Advances and Perspectives, ed. by V. Valtchev, S. Mintova, M. Tsapatsis (Elsevier, Amsterdam, 2008), p. 127

6. W.H. Dokter, H.F.V. Garderen, T.P.M. Beelen, R.A.V. Santen, W. Bras, Angew. Chem. Int. Ed. 34, 73 (1995)

7. V. Nikolakis, E. Kokkoli, M. Tirrell, M. Tsapatsis, D.G. Vlachos, Chem. Mater. 12, 845 (2000)

8. B.J. Schoeman, Zeolites. 18, 97 (1997)

9. P.-P.E.A. De Moor, T.P.M. Beelen, R.A.V. Santen, L.W. Beck, M.E. Davis, J. Phys. Chem. B. 104, 7600 (2000)

10. J.M. Fedeyko, J.D. Rimer, R.F. Lobo, D.G. Vlachos, J. Phys. Chem. B. 108, 12271 (2004)

11. A. Aerts, M. Haouas, T.P. Caremans, L.R.A. Follens, T.S. Van Erp, F. Taulelle, J. Vermant, J.A. Martens, C.E.A. Kirschhock, Chem. Eur. J. 16, 2764 (2010)

12. T.M. Davis, T.O. Drews, H. Ramanan, C. He, J. Dong, H. Schnablegger, M.A. Katsoulakis, E. Kokkoli, A.V. Mccormick, R.L. Penn, M. Tsapatsis, Nat. Mater. 5, 400 (2006)

13. S. Kumar, R.L. Penn, M. Tsapatsis, Microporous Mesoporous Mater. 144, 74 (2011)

14. A. Aerts, L.R.A. Follens, E. Biermans, S. Bals, G. Van Tendeloo, B. Loppinet, C.E.A. Kirschhock, J.A. Martens, Phys. Chem. Chem. Phys. 13, 4318 (2011)

15. J.C.A.B. Nagy, P. Bodart, H. Collette, C. Fernandez, Z. Gabelica, A. Nastro, R. Aiello, J. Chem. Soc. Faraday Trans. 85, 2749 (1989)

16. L. Itani, Y. Liu, W. Zhang, K.N. Bozhilov, L. Delmotte, V. Valtchev, J. Am. Chem. Soc. 131, 10127 (2009)

17. N. Ren, B. Subotić, J. Bronić, Y. Tang, M.D. Sikirić, T. Mišić, V. Svetličić, S. Bosnar, T.A. Jelić, Chem. Mater. 24, 1726 (2012)

18. N. Ren, S. Bosnar, J. Bronić, M.D. Sikirić, T. Mišić, V. Svetličić, J.-J. Mao, T.A. Jelić, M. Hadžija, B. Subotić, Langmuir. 30, 8570 (2014)

19. C. Liu, D. Kong, H. Guo, Microporous Mesoporous Mater. 193, $61(2014)$

20. W. Aguilar-Mamani, G. García, J. Hedlund, J. Mouzon, SpringerPlus 3, 292 (2014)

21. L.J. Gibson, M.F. Ashby, Cellular Solids: Structure and Properties. (Cambridge University Press, Cambridge, 2010)

22. S.P. Zhdanov, ACS Adv. Chem. Ser. 101, 20 (1971)

23. B.M. Lowe, Zeolites 3, 300 (1983)

24. J. van Hooff, J. Roelofsen, Stud. Surf. Sci. Catal. 58, 241 (1991)

25. G. Harvey, L. S. D. Glasser, ACS Symp. Ser. 398, 49 (1989)

26. J. Casci, B. Lowe, Zeolites 3, 186 (1983)

27. S. Yang, A. Navrotsky, Chem. Mater. 16, 3682 (2004)

28. S. Bosnar, J. Bronić, T.A. Jelić, B. Subotić, CrystEngComm 14, 3069 (2012) 